\title{
Research on the Sustainable Development of Family Enterprises in China from the Perspective of "Home Culture"
}

\author{
Yuan Zhang ${ }^{a}$, Yongjun Guan ${ }^{b}$
}

School of Management, Guangxi University of Science and Technology, Liuzhou 545006, China. asmilinglady@126.com, bsdafgjkbvc@qq.com

\begin{abstract}
For family enterprises, which are an important part of China's economic life, how to realize the sustainable development of family business and successfully complete intergenerational inheritance is a difficult problem faced by many family businesses. Improving the life expectancy of family businesses is the key to ensuring the stable development of family businesses. The traditional Chinese "home culture" has a profound impact on the intergenerational inheritance of China's family business. Therefore, this paper explores the inheritance of family business from the perspective of Chinese traditional culture, and hopes to provide some suggestions for the inheritance of family business in China.
\end{abstract}

Keywords: family business, intergenerational inheritance, home culture.

\section{Intergenerational Inheritance of Family Business and its Current Situation}

A family business refers to a company in which capital or shares are mainly controlled in the hands of a family, and family members are the main leadership positions of the company. Family business is a major component of China's private economy. The proportion of family enterprises in China's private enterprises is as high as $85 \%$, contributing 65\% of China's GDP. It plays an important role in increasing tax revenue, promoting regional economic growth, providing employment and enhancing social stability [1]. However, with the globalization of the market, how Chinese family enterprises can enhance their competitiveness, how to effectively use the external labor market, and successfully carry on intergenerational inheritance are the necessary conditions for the company to continue to grow. According to the "Report on the Inheritance of Chinese Family Enterprises, "In the next 10 years, there will be a large number of entrepreneurs retiring and the second-generation successors taking office." Whether a large number of important and important family businesses can be smoothly transferred, passed on, and further promoted is not only related to the fate of individual families and enterprises, but also to issues such as the entire national economy, employment, and even social stability.

However, in the fierce market competition and complex transformation environment, the family business incumbent faces many practical problems and challenges, such as the succession of succession of successors, the lack of experience of successors, and the neglect of professional managers. According to the survey report, the current situation of Chinese family succession is not satisfactory. Not all private entrepreneurs have perfect plans for succession: $50 \%$ of the "enterprise generation" inheritance planning is not perfect, and $25 \%$ of "enterprise generations" do not want to take over. Therefore, how to protect the successor is a major test for the family business incumbents. Intergenerational inheritance is not a simple inheritance of wealth. How to promote successors to take over the family business and continue to carry forward the family business is a common problem faced by the incumbents. Under the situation that China's economic growth slows down, reforms are comprehensively deepened, and industrial restructuring and adjustments are combined, the traditional inheritance model and system will inevitably be unable to adapt to such a complicated market situation. Innovation and reform are inevitable trends. 


\section{Problems in the Inheritance of Chinese Family Business under the Influence of "Home Culture"}

Many fundamental things in Chinese culture have not changed in the continuation of history. It is still the concept of the core of Chinese behavior. The reason why families have such an important position in traditional Chinese society is that the agricultural society uses land as the main production tool, and the protection and cultivation of land and the care and harvest of crops need to work together by the small groups of long-lasting and stable, and this small community is a blood-based family. The family has become the core of agricultural social economic life and social life. Its protection, continuation, harmony and unity are extremely important, forming a family-oriented familyism in which Chinese people pay attention to everything [2]. Therefore, the specific Chinese nation's focus on the cultural accumulation of the family will affect the choice of the organizational form of China's reality in a considerable extent and for a long time [3]. In the Chinese family complex, the prosperity of the enterprise is the embodiment of the glory of the family; and in the inheritance of the enterprise, there is also a universal logic: on the right, the leader of the family business manages the enterprise well and is worthy of the ancestors; Building a career and leaving a family business for future generations, this traditional logic under the "home culture" is the starting point for the inheritance and continuation of Chinese family businesses. China is a country with the longest and deepest tradition of "home culture". The "home culture" reflects the distinctive features of Chinese traditional culture. For this reason, the inheritance of family businesses in China is deeply influenced by the "home culture". Most of them rely on blood relationship to select heirs. This makes the family business in China have some problems in inheritance.

\subsection{The Succession of the Successor of the Enterprise is not High.}

In the traditional "family culture" ethical system, the family ethics pattern of "father as a subfamily" often affects the child's life choices. "Subsidiary fatherhood" is not only the father's will, but also the obligations and responsibilities of the children. However, with the weakening of traditional family blood ethics, the erosion of Western cultural thoughts, and the spread of information networks, today's family chain has been broken, and children have no obligation or willingness to take over and continue their careers. Therefore, in the process of inheritance of Chinese family business, the children of the founders of many family enterprises did not intend to become the heirs and managers of the family business. From the survey data, "the second generation of the family business compared to the higher willingness of the parents to succeed. The willingness to succeed is not high [4]. It is clear that the second generation who is willing to take over only accounts for $40 \%$ of the survey sample, while $15 \%$ of the second generation expressly refuses to accept the shift, and another $45 \%$ of the second generation is still in a position to take over. It is not clear." This has brought a severe test to the intergenerational inheritance of family businesses in China.

\subsection{Insufficient Ability of Enterprise Successors.}

Due to the deep influence of the traditional "home culture" in China, the family business has preferred family members in the selection and employment of people, and there is a serious phenomenon of cronyism. In corporate personnel decision-making, family members are more likely to gain recognition and take up important positions, and they are more inclined to family members in the distribution of benefits. However, the mode of fostering successors in family enterprises in China is too monotonous and inefficient, lacking systematic science. The domestic education concept is relatively backward compared with developed countries, and the education method is relatively rigid, which greatly reduces the quality of training. At the same time, due to the superior living environment of the second generation, the successors who grew up in the over-protected family environment are unable to inherit their father's business after completing their studies. They are seriously lacking in practical experience, dreams and passions, lacking quality and hard work, and cannot form. A better overall situation, long-term development thinking and vision may cause family businesses to fall into operational difficulties. There are also some family business founders who are reluctant to lose control 
of the company and are reluctant to change their successors to shake their interests. They always pay attention to or even ignore the training of successors. Many corporate successors are from the older generation of managers. After inheriting the rights, it is difficult to be competent, which eventually leads to bankruptcy.

\subsection{Professional Managers are often Excluded.}

The traditional family concept makes family businesses tend to choose members within the family in choosing people. On the one hand, family businesses are often questioned and distrusted to outsiders, because relative family members have a blood relationship to ensure that non-family members have greater uncertainty. On the other hand, family business managers are more willing to assign family members to blood-related family members in the interests of family business. Moreover, China's current contract for regulating professional managers and related systems are not perfect enough. For family businesses, the introduction of professional managers to manage enterprises lacks sufficient benefits. For this reason, family business inheritance is internal and exclusive.

\section{Suggestions}

\subsection{Improve the Willingness of Successors to take Over.}

Enhance family identity and family commitment. The Family Heritage Center of China Europe International Business School has divided the factors affecting the family's second-generation succession into three factors: self-factor, enterprise factor and family factor. Family factors such as family values and family relationships have greatly influenced the recognition and commitment of the second generation to family business [5]. As Xiujuan Li, a professor of management at CEIBS, points out: the relevance of tradition, family harmony, family prosperity and succession of descendants is very significant. When a generation is more traditional and more concerned about family happiness, it is more inclined to let the children and grandchildren pick up their classes. At the same time, the more traditional the second generation, the stronger it will be. In addition, family prosperity and family belonging are related to family involvement. When a generation is more concerned with the continuation and prosperity of the family, they are more willing to let family members control or involve the company. And if the second generation cares more about family happiness, it will enjoy the work more. The more the psychology feels that they are part of the family, the more willing to take over the family business. Therefore, the family identity and family commitment of the successor should be enhanced as early as possible to improve the willingness to succeed.

\subsection{Develop a Sound Succession Incubation Plan.}

The research on family business succession shows that the family business successors have three choices, namely internal promotion, sub-father business and professional managers. There are other factors in the family business that choose the heirs, such as the lack of suitable heirs, low family members' willingness to inherit. Therefore, family businesses should consider these factors early and develop a sound succession plan. After the family business has developed a sound succession plan, a series of measures can be taken to train the successor early. For example, Fangtai Company implements the "three-three system" of the transfer of rights that is to take three years, help three years, and see three years. Through these similar measures, we can cultivate the management ability of the successors: understand the business operations of the family business, and the market environment. Only such a successor to the family business can better compete and manage the enterprise, so that the family business can continue to develop. 


\subsection{Introduce Professional Managers Boldly and Improve the Constraints and Guarantee Mechanisms of Professional Managers.}

Family businesses want to survive, grow and develop, and it is not enough to rely solely on members of the family. Professional managers have many advantages that family members can't match in the family business management process. For example, professional managers first consider the interests of the company rather than the interests of a member of the family members in the daily operational decisions of the company. The professional management knowledge and rich management of professional managers can make the family business more viable. Good professional managers often have a lot of connections, which is very helpful for the business development of family businesses. Therefore, the business owners of family businesses should abandon the narrow family concept and open their eyes. It is actively introduced when family businesses need to introduce professional managers, and contributes to the flourishing development of family businesses in the future. The introduction of professional managers is conducive to solving the "bottleneck" faced by the development of enterprises. In addition, it should also establish a matching professional manager restraint and guarantee mechanism, and do a good job of incentive measures while restricting the behavior of professional managers, and effectively improve the enthusiasm of professional managers.

\section{Summary}

Under the influence of "home culture", the inheritance of family businesses in China is generally restricted to families and families to prevent the loss of family or family property. However, according to statistics, the average life expectancy of Chinese family businesses is only 24 years. At present, less than $30 \%$ of family businesses can enter the second generation, less than $10 \%$ can enter the third generation, and only about $4 \%$ enter the fourth generation. It can be seen that the inheritance efficiency of family enterprises in China is relatively low, and the most important problem is that the successor's willingness to take over is not high or the ability is insufficient, and the older generation is more exclusive to professional managers. This is also the "bottleneck" faced by Chinese family businesses. However, there is no such thing as a correct model for intergenerational inheritance. For Chinese family businesses that are in the growth stage, according to the actual situation, we will do a good job of successor training plans and arrangements, improve the willingness and ability of successors, and set a good stage assessment. If there are multiple successors, you can choose to use them. If you are not qualified, you should consider introducing professional managers. You can also introduce professional managers to guide the successors until the successors can be competent leaders and managers. In short, finding the right path to inherit is the most successful and safest choice.

\section{References}

[1]. Shan Jiayuan,Qianyi. The dilemma of intergenerational inheritance of family business in China and its countermeasures[J].Economist, 2017(04):269-270.

[2]. Zhou Yan, Su Xuemei.The Cultural Motivation and Dilemma of the Inheritance of Chinese Family Enterprises[J]. Realistic,2011(08):49-52.

[3]. Wang Qingju.Problems and Countermeasures in the Intergenerational Succession of Family Enterprises in China[J].Journal of Taishan University,2014,36(01):73-76.

[4]. Zhu Chunfei. Research and Analysis on the Influencing Factors of Children's Willingness to Take Over in Zhejiang Family Enterprises[J].Knowledge Economy,2015(23):13-14.

[5]. Yang Yun. The influence of "home" culture on the intergenerational inheritance of family business [J]. Science and Education Wenhui (first issue), 2017 (06): 186-188. 